The native anomalous phasing method will have greatest application to cases where poor occupancy or multiple substitution occurs, making direct interpretation of isomorphous difference Pattersons difficult. Alternatively, this method may be useful for locating relative origins for the binding sites from several derivatives in unfavorable space groups, such as $P 1$. The major reasons for the success of the method are that full occupancy of the native anomalous scatterer always occurs, the number and types of binding sites are chemically defined, and the X-ray data are inherently more accurate, since no scaling is needed for anomalous pairs and lack of isomorphism never occurs.

The authors wish to thank Drs B. Matthews and G. Kartha for helpful discussions. This work has been supported by NSF Grant No. GB27683 and Life Insurance Medical Research Fund No. G-70-28. P.A. was supported by a U.S.P.H.S. postdoctoral fellowship.

\section{References}

Blow, D. M. \& Crick, F. H. C. (1959). Acta Cryst. 12, 794-802.
Blow, D. M. \& Rossmann, M. G. (1961). Acta Cryst. 14, 1195-1202.

Buerger, M. J.(1959). Vector Space. New York: John Wiley. Czerwinski, E. W., Mathews, F. S., Hollenberg, P., Drickamer, K. \& Hager, L. P. (1972). J. Mol. Biol. 71, 819-821.

International Tables for X-ray Crystallography (1962). Vol. III p. 213. Birmingham: Kynoch Press.

Kartha, G. (1961). Acta Cryst. 14, 680-686.

Kraut, J., Strahs, G. \& Freer, S. T. (1968). In Structural Chemistry and Molecular Biology, edited by A. RICH \& N. DAvidson, p. 55. San Francisco: Freeman.

Mathews, F. S., Levine, M. \& Argos, P. (1972). J. Mol. Biol. 64, 449-464.

Matthews, B. W. (1966). Acta Cryst. 20, 82-86.

Matthews, B. W. (1969). In Crystallographic Computing, edited by F. R. AHMED, p. 146. Copenhagen: Munksgaard.

NoRTh, A. C. T. (1965). Acta Cryst. 18, 212-216.

Strahs, G. \& Kraut, J. (1968). J. Mol. Biol. 35, 503512.

Wilson, A. J. C. (1942). Nature, Lond. 150, 152.

WyCKoFf, H. W., Doscher, M., Tsernoglow, D., INAgami, T., Johnson, L. N., Hardman, K. D., Allewell, N. M., Kelly, D. M., \& Richards, F. M. (1967). J. Mol. Biol. 27, 563-578.

Acta Cryst. (1973). B29, 1611

\title{
Peri Interactions: An X-ray Crystallographic Study of the Structure of 1,8-Bis(dimethylamino)naphthalene*
}

\author{
By Howard Einspahr, $\dagger$ J.-B. Robert, $₫$ Richard E. MARSH ANd John D. Roberts \\ Gates, Crellin, and Noyes Laboratories of Chemistry, \\ California Institute of Technology, Pasadena, California 91109, U.S.A.
}

(Received 11 December 1972; accepted 21 February 1973)

\begin{abstract}
Crystals of 1,8-bis(dimethylamino)naphthalene, $\mathrm{C}_{14} \mathrm{H}_{18} \mathrm{~N}_{2}$, are orthorhombic, space group $P 22_{1} 2_{1} 2_{1}$, with $a=12.855(1), b=10 \cdot 110(1), c=9.664$ (1) $\AA$ and $Z=4$. A complete structure determination, including refinement of the positions of the hydrogen atoms, led to an $R$ index of 0.053 and a goodness-offit of 2.02 for 1477 reflections. The molecule adopts a conformation in which one carbon atom of each of the dimethylamino groups is eclipsed with respect to the naphthalene ring. Hindrance between the dimethylamino groups and/or resonance interactions between the dimethylamino groups and the aromatic ring are sufficiently great to distort the ring in several ways, the most conspicuous being a sizable increase in the non-bonded $C(1) \cdots C(8)$ distance $(2.56 \AA)$ compared to the $C(4) \cdots C(5)$ distance $(2.44 \AA)$ and a twisting of the naphthalene ring into a considerably nonplanar conformation.
\end{abstract}

\section{Introduction}

The title compound, $N, N, N^{\prime}, N^{\prime}$-tetramethyl-1,8-diaminonaphthalene (I), is especially interesting for its un-

* Contribution No. 4507 from the Division of Chemistry and Chemical Engineering, California Institute of Technology. This work was supported in part by a grant from the National Science Foundation, and in part by grant GM 16966 from the Division of General Medical Sciences, Public Health Services. $\dagger$ Present address: Institute for Dental Research, University of Alabama Medical School, Birmingham, Alabama, U.S.A.

† Present address: Centre d'Etudes Nucléaires de Grenoble, 38-Grenoble, France. usual basic properties ('the proton sponge'; Alder, Bowman, Steele \& Winterman, 1968) and for the steric effects which are expected to be encountered and their influence on the conformation that the molecule will find most favorable. Normally, there is strong resonance interaction between a dimethylamino group and an aromatic ring, so that one might expect a planar conformation to be favored (cf., e.g. Wheland, 1955). However, because of the steric difficulties for compounds such as (I), there is no reasonable possibility of bringing even one of the dimethylamino groups into the plane of the ring. Alternative possibilities include (II), where 
the methyl groups are out of one another's way but the nitrogen lone pairs are brought face to face; (III), where the lone pairs are favorably situated relative to one another but one pair of methyl groups interferes strongly with a nitrogen atom; and (IV), a compromise achieved at the expense of some interference between one methyl group on each nitrogen atom and the hydrogens at positions 2 and 7. A further question concerns the amount of $\pi$ character in the $\mathrm{C}$ (ring)- $\mathrm{N}$ bonds, and whether it might be sufficient to force the nitrogen atoms into planar configurations. Because of our interest in these questions, and the general interest in peri interactions (Balasubramaniyan, 1966; Anderson, Franck \& Mandella, 1972), we have undertaken an X-ray diffraction study of $\mathrm{I}$.<smiles>CN(C)c1cccc2cccc(N(C)C)c12</smiles>

(I)

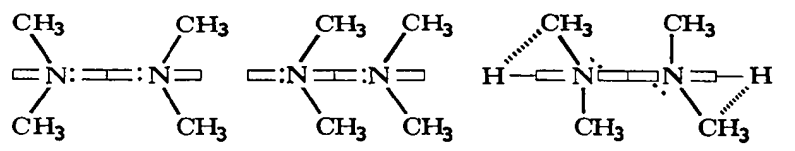
(II) (III)

(IV)

\section{Experimental}

Crystals were obtained by evaporation of a solution of I (Aldrich) in methanol at room temperature. Preliminary film work indicated orthorhombic symmetry; systematic absence of reflections $h 00,0 k 0$ and $00 l$ with $h, k$ or $l$ odd is characteristic of the space group $P 2_{1} 2_{1} 2_{1}$. Lattice constants were obtained from a least-squares fit to 16 carefully centered $2 \theta$ values ranging between 40 and $85^{\circ}$, measured on a quarter-circle diffractometer at $23(2)^{\circ} \mathrm{C}$ using $\mathrm{Cu} K \alpha$ radiation. The density was measured by flotation in an aqueous solution of $\mathrm{ZnBr}_{2}$. Crystal data are given in Table 1.

Table 1. Crystal data

Orthorhombic

Space group, $P 22_{1} 2_{1} 2_{1}$

$a=12 \cdot 855$ (1) $\AA$

$b=10 \cdot 110$ (1)

$c=9 \cdot 664(1)$

$\lambda(\mathrm{Cu} K \alpha)=1 \cdot 5418 \AA$

$$
\begin{aligned}
& \mathrm{C}_{14} \mathrm{H}_{18} \mathrm{~N}_{2} \\
& \mathrm{~F} . \mathrm{W} .214 \cdot 3 \\
& \varrho_{\text {meas }}=1 \cdot 12(1) \mathrm{g} \mathrm{cm}^{-3} \\
& \varrho_{\text {calc }}=1 \cdot 13 \mathrm{~g} \mathrm{~cm}^{-3} \\
& Z=4 \\
& F(000)=464 \\
& u / Q=4 \cdot 63 \mathrm{~cm}^{2} \mathrm{~g}^{-1} \text { (for } \mathrm{Cu} K \alpha \\
& \text { radiation) }
\end{aligned}
$$

The crystals used in the film work were exposed to the air, and suffered rather rapid decomposition. Accordingly, the crystal used to collect intensity data was enclosed in a thin-wall glass capillary (Raebiger) under an argon atmosphere. It was a rectangular prism with dimensions of about $0.1 \times 0.2 \times 0.4 \mathrm{~mm}$, mounted with its long dimension (the $c$ axis) slightly canted with respect to the $\varphi$ axis of the diffractometer. Two data sets were collected. The first set, which was the basis for the solu-

tion and initial refinement of the structure, comprised 720 independent reflections, out to $40^{\circ}$ in $2 \theta$, collected using graphite-monochromated Mo $K \alpha$ radiation and an automated full-circle diffractometer operating in a $\theta-2 \theta$ scan mode at a variable scan speed. Since the counting statistics were poor and many of the measured intensities lay near the threshold of significance, a second data set was collected using a highly modified Datex-automated General Electric XRD-5 diffractometer operating with Ni-filtered $\mathrm{Cu} K \alpha$ radiation, a quarter-circle goniostat, scintillation counter and pulseheight analyzer. Four octants of reciprocal space out to $2 \theta=147^{\circ}$ were surveyed using a $\theta-2 \theta$ scan at a rate of $1^{\circ}$ (in $2 \theta$ ) per minute, background counts of $20 \mathrm{sec}$ at each extremum, and a scan range which increased from $2 \cdot 0^{\circ}$ for all reflections with $2 \theta \leq 50^{\circ}$ to $4 \cdot 0^{\circ}$ at $2 \theta=150^{\circ}$. Since an important aspect of the investigation lay in determining reliable positions for the hydrogen atoms, the measurements were repeated two more times for all reflections with $2 \theta \leq 50^{\circ}$, once with the intensity of the X-ray beam reduced by about $50 \%$ (in order to check on coincidence losses and counter overflow). Three standard reflections were monitored continually. During the 27 days of data collection, they showed a small, linear decay, the intensities dropping to about $96 \%$ of their initial values. The measured intensities and their standard deviations were adjusted to compensate for this decay and, where necessary, for the reduction in beam intensity. Observational variances $\sigma^{2}(I)$ were assigned on the basis of counting statistics plus an additional term $(0.02 S)^{2}$, where $S$ is the scan count.

At this stage, the data were perused very carefully; while no formal statistics were collected, it appeared that the general agreement among the equivalent observations was within the assigned errors. There was no indication of coincidence loss for the strong intensities; however, it was apparent that the 110 and 102 reflections had exceeded the counter capacity ( $10^{7}$ counts), even at reduced beam intensity. These two intensities were corrected for the overflow, but were assigned artificially low weights during subsequent refinements. In addition, the 012 reflection had overflowed the counter when collected at normal beam intensity, and one measurement (of a total of approximately 7900) was obviously faulty because of failure of the instrumentation.

Intensities from the four different octants were then averaged, the small effects of anomalous dispersion being ignored. Thus, 12 sets of measurements entered into the final values of $F^{2}$ for most of the low-angle data, and four for the high-angle reflections. Weights were taken as the sum of the weights of the individual measurements, but only up to a total five (this admittedly arbitrary limit was established in order that the contribution of systematic errors and of deficiencies in the theoretical model, as represented by the term $(0.02 S)^{2}$, would not be negated for the low-angle data). The total number of independent reflections was 1477 . Of these, 81 averaged intensities were less than zero, 
Table 2. Positional and thermal parameters

Parameters for $\mathrm{C}(1)$ to $\mathrm{C}(16)$ are multiplied by $10^{4}$. Anisotropic temperature factors are expressed as: E.s.d.'s are in parentheses.

\begin{tabular}{|c|c|c|c|c|}
\hline & $x$ & $y$ & $z$ & $\beta_{11}$ \\
\hline$C(1)$ & $1863(2)$ & $926(2)$ & $1416(2)$ & $66(2)$ \\
\hline$C(2)$ & $1591(2)$ & 2208 (3) & $1760(3)$ & $85(3)$ \\
\hline$C(3)$ & $2336(3)$ & 3191 (3) & $1906(3)$ & $117(3)$ \\
\hline C(4) & 3339 (3) & 2938 (3) & $1656(3)$ & $107(2)$ \\
\hline$C(5)$ & $4727(2)$ & $1396(3)$ & $1043(3)$ & $77(2)$ \\
\hline$C(6)$ & $5057(2)$ & $172(4)$ & $780(3)$ & $57(2)$ \\
\hline$C(7)$ & 4379 (2) & $-919(3)$ & $893(3)$ & 87 (2) \\
\hline$C(8)$ & 3347 (2) & $-755(3)$ & $1215(2)$ & $66(2)$ \\
\hline C(9) & $2938(2)$ & $577(2)$ & $1319(2)$ & $58(2)$ \\
\hline$C(10)$ & $3672(2)$ & $1633(2)$ & $1344(2)$ & $65(2)$ \\
\hline$N(11)$ & 1087 (1) & $-6(2)$ & $1154(2)$ & $56(1)$ \\
\hline$N(12)$ & $2695(2)$ & $-1841(2)$ & $1447(2)$ & $92(2)$ \\
\hline$C(13)$ & $1077(3)$ & $-618(3)$ & $-222(3)$ & 79 (2) \\
\hline$C(14)$ & $35(2)$ & $268(4)$ & $1638(4)$ & $67(3)$ \\
\hline$C(15)$ & $3024(4)$ & $-3125(4)$ & $918(4)$ & $149(4$ \\
\hline$C(16)$ & $2210(3)$ & $-1947(3)$ & $2814(3)$ & 104 \\
\hline
\end{tabular}
$\exp \left\{-\left(h^{2} \beta_{11}+k^{2} \beta_{22}+l^{2} \beta_{33}+h k \beta_{12}+h l \beta_{13}+k l \beta_{23}\right)\right\}$

\begin{tabular}{rrrrrrr}
$z$ & \multicolumn{1}{c}{$\beta_{11}$} & \multicolumn{1}{c}{$\beta_{22}$} & \multicolumn{1}{c}{$\beta_{33}$} & $\beta_{12}$ & \multicolumn{1}{c}{$\beta_{13}$} & \multicolumn{1}{c}{$\beta_{23}$} \\
$1416(2)$ & $66(2)$ & $102(3)$ & $91(3)$ & $-18(4)$ & $10(4)$ & $2(5)$ \\
$1760(3)$ & $85(3)$ & $113(3)$ & $148(4)$ & $10(5)$ & $18(5)$ & $-13(5)$ \\
$1906(3)$ & $117(3)$ & $106(3)$ & $183(5)$ & $13(5)$ & $26(6)$ & $-31(7)$ \\
$1656(3)$ & $107(2)$ & $108(3)$ & $136(4)$ & $-77(5)$ & $-5(5)$ & $10(6)$ \\
$1043(3)$ & $77(2)$ & $175(4)$ & $141(4)$ & $-45(5)$ & $-7(5)$ & $46(7)$ \\
$780(3)$ & $57(2)$ & $234(5)$ & $172(4)$ & $8(6)$ & $23(5)$ & $52(8)$ \\
$893(3)$ & $87(2)$ & $145(4)$ & $152(4)$ & $54(5)$ & $20(5)$ & $4(7)$ \\
$1215(2)$ & $66(2)$ & $113(3)$ & $93(3)$ & $10(4)$ & $4(4)$ & $6(5)$ \\
$1319(2)$ & $58(2)$ & $99(2)$ & $83(2)$ & $-15(3)$ & $8(4)$ & $9(5)$ \\
$1344(2)$ & $65(2)$ & $126(3)$ & $95(3)$ & $-28(4)$ & $-7(4)$ & $29(5)$ \\
$1154(2)$ & $56(1)$ & $127(2)$ & $117(3)$ & $-32(3)$ & $20(3)$ & $-13(5)$ \\
$1447(2)$ & $92(2)$ & $87(2)$ & $125(3)$ & $3(3)$ & $1(4)$ & $3(5)$ \\
$-222(3)$ & $79(2)$ & $162(4)$ & $128(4)$ & $-34(5)$ & $-32(5)$ & $-32(7)$ \\
$1638(4)$ & $67(3)$ & $211(5)$ & $185(5)$ & $-17(6)$ & $35(6)$ & $-8(9)$ \\
$918(4)$ & $149(4)$ & $112(3)$ & $205(6)$ & $51(7)$ & $-27(8)$ & $-36(8)$ \\
$2814(3)$ & $104(3)$ & $137(4)$ & $141(4)$ & $-41(6)$ & $16(6)$ & $57(7)$
\end{tabular}

none by more than $2 \cdot 7 \sigma(I)$. Finally, the intensities and their standard deviations were corrected for Lorentz and polarization effects, but not for absorption $\left(\mu t_{\max } \simeq 0 \cdot 2\right)$.

\section{Structure determination and refinement}

A three-dimensional Patterson map was calculated from the first $(\mathrm{Mo})$ data set. Examination of sections at $w=0$ and $w=\frac{1}{4}$ indicated that the molecular plane lies approximately perpendicular to $\mathrm{c}$ and at $z \simeq \frac{1}{8}$. The position and orientation of the molecule were derived by fitting a calculated vector map of a 1,8-disubstituted naphthalene grouping to the e two Patterson sections. A structure-factor calculation for this model produced an $R$ index, $\sum|| F_{o}|-| F_{c}|| / \sum\left|F_{o}\right|$, of 0.65 . A subsequent electron-density map showed peaks for the four methyl carbon atoms, completing the heavy-atom model.

The full-matrix least-squares refinements which followed minimized the function $\sum w\left[F_{o}^{2}-\left(1 / K^{2}\right) F_{c}^{2}\right]^{2}$, where $w=1 / \sigma^{2}\left(F_{o}^{2}\right)$. Refinement with the Mo data was discontinued after several cycles on an isotropic model when it became clear that the number and quality of these data were insufficient to justify continuing. Refinement was resumed after the $\mathrm{Cu}$ data were collected. After two cycles of isotropic refinement, difference Fourier maps revealed the positions of all the hydrogen atoms. Subsequent refinement, which included as parameters the positions and anisotropic temperature factors of the heavy atoms, the positions and isotropic temperature factors of the hydrogen atoms, a secondary extinction coefficient [Larson, 1967, equation (3)], and a scale factor $K$, converged in five cycles, when no shift was as much as $20 \%$ of its e.s.d. The final $R$ index for the 1396 reflections with net intensities greater than zero is 0.053 ; the goodness-of-fit, based on all 1477 measured intensities and 218 parameters, is $2 \cdot 02$. A three-dimensional difference map showed no feature as large as \pm 0.2 e $\AA^{-3}$. Final values of the parameters are listed in Table 2, and of the observed and calculated structure factors in Table 3.
Table 2 (cont.)

Positional parameters for hydrogen atoms are multiplied by $10^{3}$.

$\begin{array}{lrrrr} & x & y & z & B\left(\AA^{2}\right) \\ \mathrm{H}(17) & 78(2) & 241(2) & 187(2) & 6 \cdot 7(6) \\ \mathrm{H}(18) & 210(2) & 412(2) & 209(3) & 7 \cdot 5(7) \\ \mathrm{H}(19) & 393(2) & 357(2) & 164(3) & 6 \cdot 8(6) \\ \mathrm{H}(20) & 524(2) & 223(2) & 108(3) & 7 \cdot 7(7) \\ \mathrm{H}(21) & 575(2) & -7(2) & 62(3) & 8 \cdot 5(8) \\ \mathrm{H}(22) & 462(2) & -182(2) & 75(2) & 5 \cdot 1(6) \\ \mathrm{H}(31) & 65(2) & -7(2) & -79(3) & 7 \cdot 8(8) \\ \mathrm{H}(32) & 82(2) & -160(3) & -13(3) & 8 \cdot 2(8) \\ \mathrm{H}(33) & 180(2) & -70(2) & -54(2) & 5 \cdot 7(6) \\ \mathrm{H}(41) & -37(2) & -58(2) & 148(3) & 8 \cdot 8(9) \\ \mathrm{H}(42) & -34(2) & 99(2) & 108(3) & 8 \cdot 1(8) \\ \mathrm{H}(43) & 7(2) & 69(2) & 266(3) & 8 \cdot 3(8) \\ \mathrm{H}(51) & 224(2) & -363(3) & 90(3) & 10 \cdot 3(10) \\ \mathrm{H}(52) & 328(2) & -299(3) & -1(3) & 9 \cdot 2(10) \\ \mathrm{H}(53) & 364(2) & -355(3) & 150(3) & 8 \cdot 7(8) \\ \mathrm{H}(61) & 149(2) & -241(3) & 268(3) & 9 \cdot 9(9) \\ \mathrm{H}(62) & 200(2) & -98(2) & 318(2) & 7 \cdot 0(7) \\ \mathrm{H}(63) & 266(2) & -243(3) & 346(3) & 9 \cdot 8(9)\end{array}$

Computations were carried out on an IBM 370-155 computer under the CRYM system. Form factors for $\mathrm{C}$ and $\mathrm{N}$ were from International Tables for X-ray Crystallography (1962) and for $\mathrm{H}$ from Stewart, Davidson \& Simpson (1965).

The pro forma values of the e.s.d.'s of the coordinates (Table 2) lead to e.s.d.'s in the bond distances that range from 0.003 to $0.004 \AA$ for bonds involving $C(1)$ and $\mathrm{C}(8)$, and from 0.004 to $0.005 \AA$ for bonds between other pairs of heavy atoms. On the other hand, the differences between bond lengths expected to be equivalent - particularly within the naphthalene ring - suggest that the e.s.d.'s should be approximately twice as large. We do not understand this discrepancy; we can only suggest that the effects of bonding electrons or aspherical atomic wave functions may be especially pronounced in this instance, in which the relatively high temperature factors make the low-angle data of greater importance. To support this thesis, we note that the weighted residuals for the low-angle data tend to be 
larger than those for the high-angle data; however, attempts to alter the weighting function so as to decrease the influence of the low-angle data did not lead to closer agreement between equivalent bond distances. In any event, we choose to quote a pragmatic value of about $0.008 \AA$ as the e.s.d.'s for bond distances between heavy atoms, and about $0.05 \AA$ for bonds involving hydrogen atoms.

\section{Results and discussion}

The molecule adopts a conformation similar to IV (see Introduction), but with the dimethylamino groups rotated so as to bring two of the methyl groups into the plane of the naphthalene ring. A drawing of the molecule, viewed along the central $C(9)-C(10)$ bond, is shown in Fig. 1; the most important non-bonded inter-

Table 3. Values of $F_{o}, F_{c}$ and $\sigma\left(F_{o}\right)($ all $\times 50)$

A minus sign preceding $F_{o}$ indicates that the measured value of $F^{2}$ was negative, by the amount $-F_{o}^{2}$. Standard deviations $\sigma\left(F_{o}\right)$ were evaluated from the relationship $\sigma\left(F_{o}\right)=\left\{\left|F_{o}^{2}\right|+\sigma\left(F_{o}^{2}\right)\right\}^{1 / 2}-\left|F_{o}\right|$. Artificially high standard deviations were assigned to the intensities of the 110 and 102 reflections, which exceeded the capacity of the counter. The final value of the secondary extinction parameter $g$ [Larson, 1967, equation (3)] is $1.04(6) \times 10^{-5} \mathrm{e}^{-2}$.
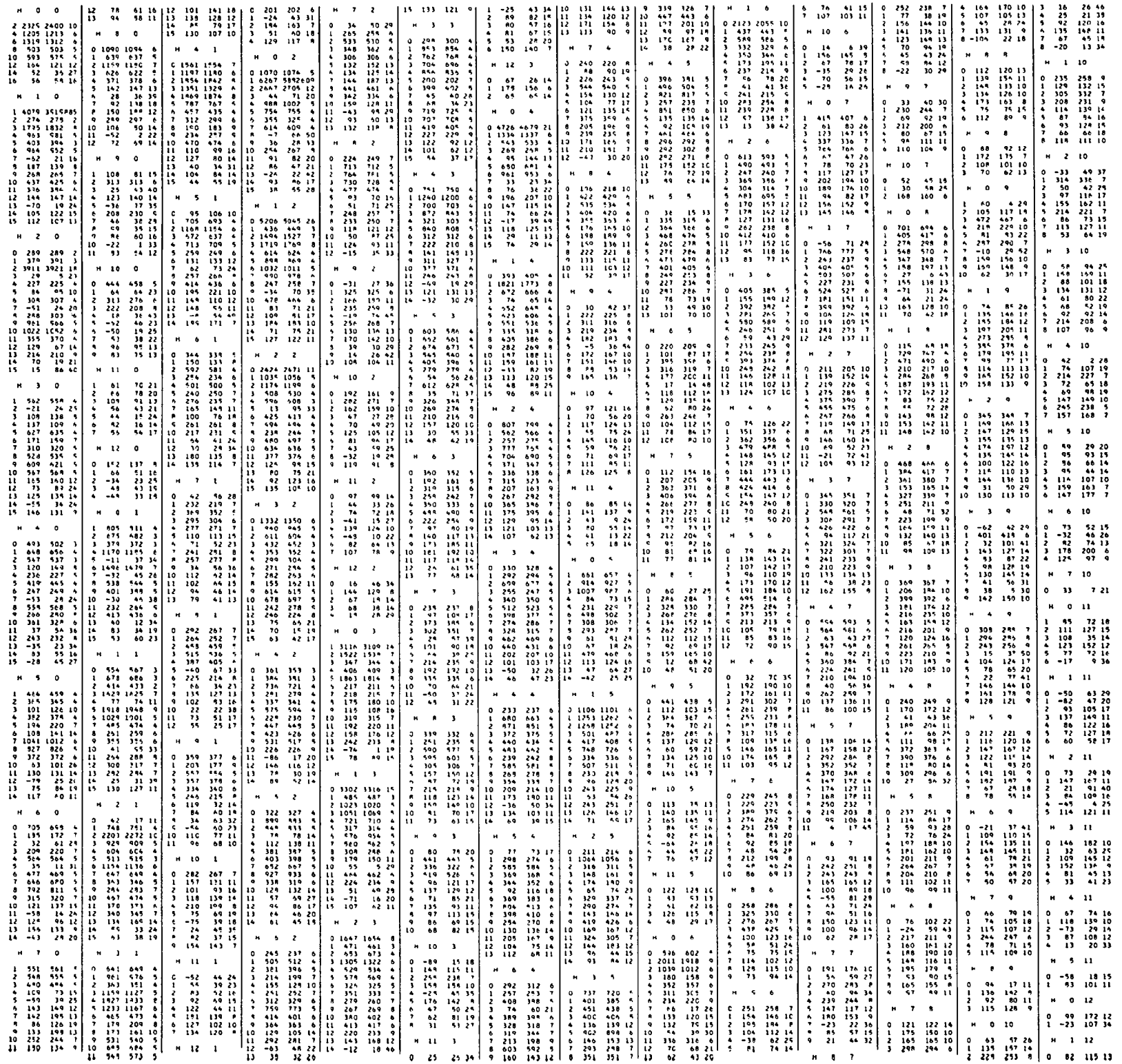
atomic contacts are included. Bond distances and angles are shown in Fig. 2(a) and (b), and in Table 4.

Table 4. Carbon-hydrogen bond distances $(\AA)$

$$
\text { E.s.d.'s are about } 0.05 \AA \text {. }
$$

$\begin{array}{llll}\mathrm{C}(2)-\mathrm{H}(17) & 1.07 & \mathrm{C}(14)-\mathrm{H}(41) & 1.02 \\ \mathrm{C}(3)-\mathrm{H}(18) & 1.00 & \mathrm{C}(14)-\mathrm{H}(42) & 1.02 \\ \mathrm{C}(4)-\mathrm{H}(19) & 0.99 & \mathrm{C}(14)-\mathrm{H}(43) & 1.08 \\ \mathrm{C}(5)-\mathrm{H}(20) & 1.07 & \mathrm{C}(15)-\mathrm{H}(51) & 1.13 \\ \mathrm{C}(6)-\mathrm{H}(21) & 0.93 & \mathrm{C}(15)-\mathrm{H}(52) & 0.96 \\ \mathrm{C}(7)-\mathrm{H}(22) & 0.97 & \mathrm{C}(15)-\mathrm{H}(53) & 1.06 \\ \mathrm{C}(13)-\mathrm{H}(31) & 0.96 & \mathrm{C}(16)-\mathrm{H}(61) & 1.04 \\ \mathrm{C}(13)-\mathrm{H}(32) & 1.05 & \mathrm{C}(16)-\mathrm{H}(62) & 1.07 \\ \mathrm{C}(13)-\mathrm{H}(33) & 0.98 & \mathrm{C}(16)-\mathrm{H}(63) & 0.98\end{array}$

The $\mathrm{C}$ (ring) $-\mathrm{N}$ bond lengths, which average $1.398 \pm 0.006 \AA$, correspond to about $20 \%$ double-bond character (see, for example, Marsh, Bierstedt \& Eichhorn, 1962). Further evidence of the $\pi$ character of these bonds lies in the $\mathrm{C}-\mathrm{N}-\mathrm{C}$ angles, for which the average value of $116^{\circ}$ is appreciably larger than expected for pure $s p^{3}$ hybridization. A striking feature of the $\mathrm{C}-\mathrm{C}$ bond distances within the naphthalene ring is the asymmetry across the plane bisecting the $C(9)-C(10)$ bond: the four bonds involving $C(4)$ and $\mathrm{C}(5)$ average about $0.035 \AA$ shorter than the corresponding bonds involving $C(1)$ and $C(8)$. This effect is presumably due to two causes: the partial double-bond character of the $\mathrm{C}-\mathrm{N}$ bonds, which leads to a withdrawal of ring-bonding electrons at $C(1)$ and $C(8)$, and bond stretching caused by overcrowding at this end of the molecule. Similar effects are found in crystal-structure studies of 3-bromo-1,8-dimethylnaph thalene (Jameson \& Penfold, 1965), 1,8-dinitronaphthalene (Akopyan, Kitaigorodskii \& Struchkov, 1965) and 1,8-bis(bromomethyl)naphthalene (Robert, Sherfinski \& Roberts, 1973), although investigators of the first structures attach no significance to these differences in bond distances.

The relative importance of strain and electronic effects in producing elongation of the $\mathrm{C}(1)-\mathrm{C}(8)$ and shortening of the $\mathrm{C}(4)-\mathrm{C}(5)$ distances compared to

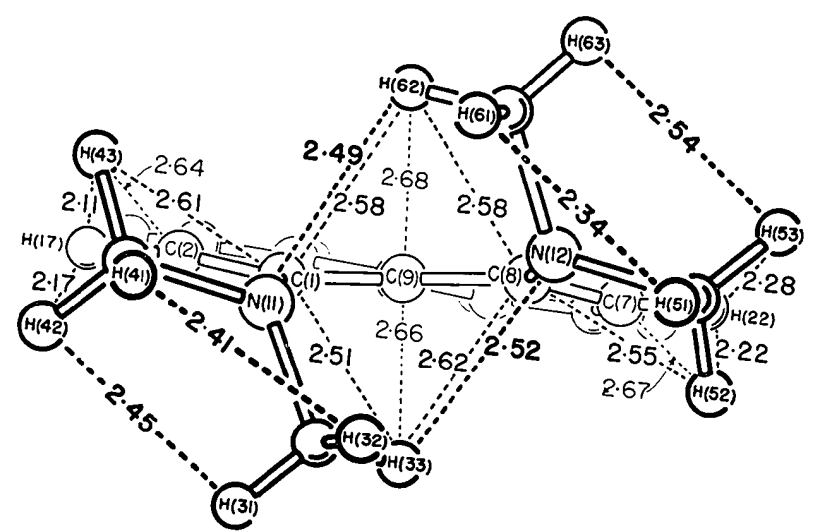

Fig. 1. A representation of the molecule viewed along the $\mathrm{C}(9)-\mathrm{C}(10)$ bond, including selected intramolecular nonbonded distances. E.s.d.'s are about $0.05 \AA$ for the $\mathrm{C}-\mathrm{H}$ and $\mathrm{N}-\mathrm{H}$ distances and about $0.07 \AA$ for the $\mathrm{H}-\mathrm{H}$ distances. naphthalene itself is not clear because, for some of the bonds. both seem to operate in the same direction Simple HMO calculations (Roberts, 1961) predict that

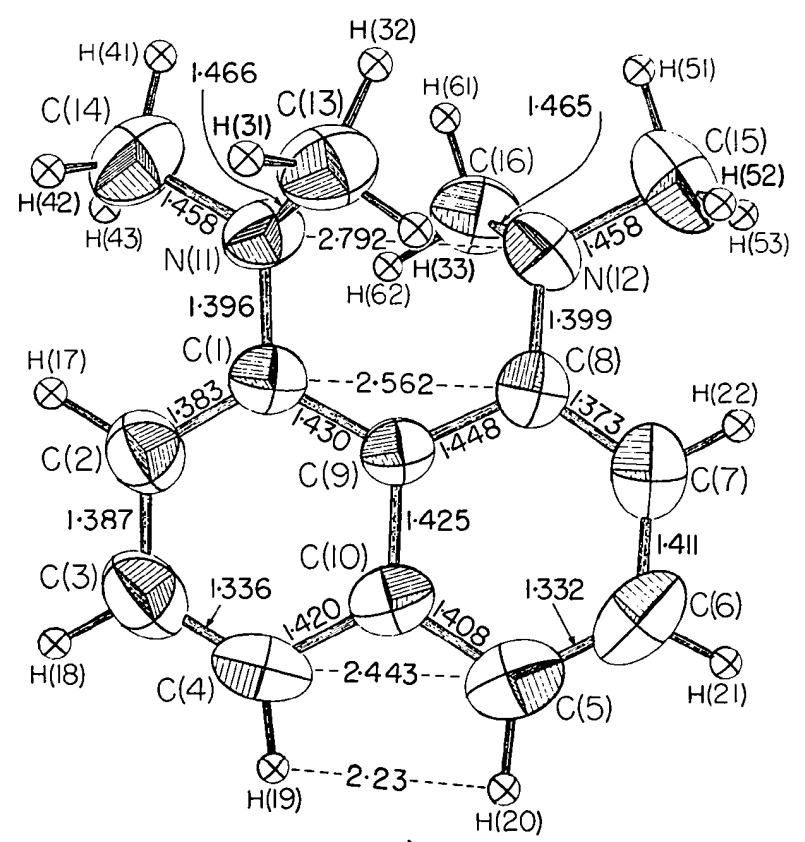

(a)

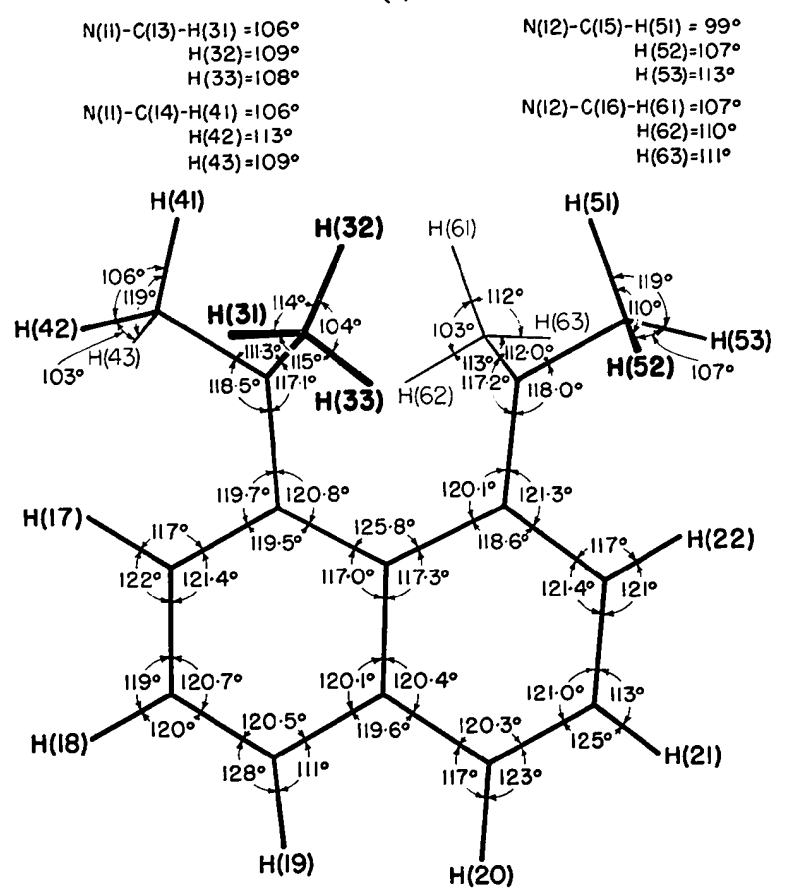

(b)

Fig. 2. (a) An ORTEP (Johnson, 1965) representation of the molecule, including all $\mathrm{C}-\mathrm{C}$ and $\mathrm{C}-\mathrm{N}$ bond distances $(\AA)$ and selected intramolecular non-bonded distances $(\AA)$. E.s.d.'s for the heavy atom distances are about $0.008 \AA$ (see text). Ellipsoids are drawn at the $50 \%$ probability level. (b) Bond angles. E.s.d.'s for angles involving only $\mathrm{C}$ and $\mathrm{N}$ atoms are about $0.3^{\circ}$; e.s.d.'s for angles involving $\mathrm{H}$ atoms are between 3 and $5^{\circ}$. 
conjugation involving the nitrogen unshared pairs and the naphthalene ring will tend, principally, to lengthen the $C(1)-C(2)$ and $C(1)-C(9)$ bonds. The observed bond-distance changes are in only fair agreement, especially since the largest change is in the $\mathrm{C}(3)-\mathrm{C}(4)$ bond which is quite substantially shortened.

Bond-angle distortion seems to be surprisingly small. Compared to the values found in a neutron-diffraction study of perdeuterionaphthalene (Pawley \& Yeats, 1969), the $C(1)-C(9)-C(8)$ angle is enlarged by about $4^{\circ}$ and both the $\mathrm{C}$ (ring)- $\mathrm{N}$ bonds have been bent outwards by about $2^{\circ}$. The close contacts of methyl groups $C(14)$ and $\mathrm{C}(15)$ with the ring hydrogen atoms $\mathrm{H}(17)$ and $\mathrm{H}(22)$ presumably prevent further expansion of the bond angles $\mathrm{C}(9)-\mathrm{C}(1)-\mathrm{N}(11)$ and $\mathrm{C}(9)-\mathrm{C}(8)-\mathrm{N}(12)$.

A principal mechanism for relief of the interactions between the dimethylamino groups is the out-of-plane distortion of the naphthalene ring. Deviations of the heavy atoms from the best plane of the ring atoms $C(1)-$ $\mathrm{C}(10)$ are shown in Fig. 3. These deviations represent primarily a twist about the central $C(9)-C(10)$, which remains a twofold symmetry axis essentially within experimental error. The twist, together with the bond-angle and bond-stretching distortions, result in increasing the non-bonded $\mathrm{N}$... N distance by about $0.35 \AA-$ from $2 \cdot 44 \AA$, as projected from the structure of perdeuterionaphthalene, to $2.79 \AA$. The $\mathrm{N}(11) \cdots \mathrm{N}(12)$ distance of $2.79 \AA$ apparently does not in itself indicate marked steric hindrance. The $\mathrm{N}$... $\mathrm{N}$ van der Waals radius estimated by Bondi (1964) is $3 \cdot 10 \AA$, and if one

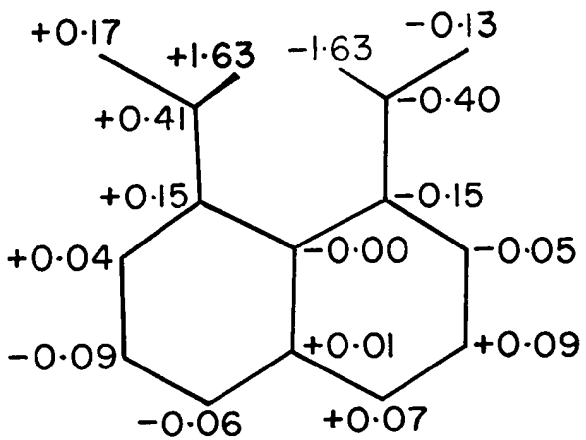

Fig. 3. Deviations $(\AA)$ from the mean plane of the ring system. Direction cosines of the plane normal relative to the $a, b$, and $c$ axes, are $-0.1360,0.1341$, and -0.9816 , respectively; the origin-to-plane distance is $-1.692 \AA$.

uses the parameters for the exp-6 equation for nonbonded interactions developed by the procedure of Scott \& Scheraga (1965), 2.79 $\AA$ corresponds to very slight attraction between the nitrogens. Indecd, even $2.44 \AA$ would correspond to only $2.4 \mathrm{kcal}$ of repulsion energy between the nitrogens. Thus, either the exp-6 parameters calculated by the Scott \& Scheraga procedure are not reliable or else $\mathrm{N} \cdots \mathrm{N}$ repulsion itself is not the most important interaction in determining the molecular geometry. An alternative may be the combination of $\mathrm{CH}_{3} \cdots \mathrm{H}$ and $\mathrm{CH}_{3} \cdots \mathrm{N}$ repulsions which result from steric inhibition of resonance.

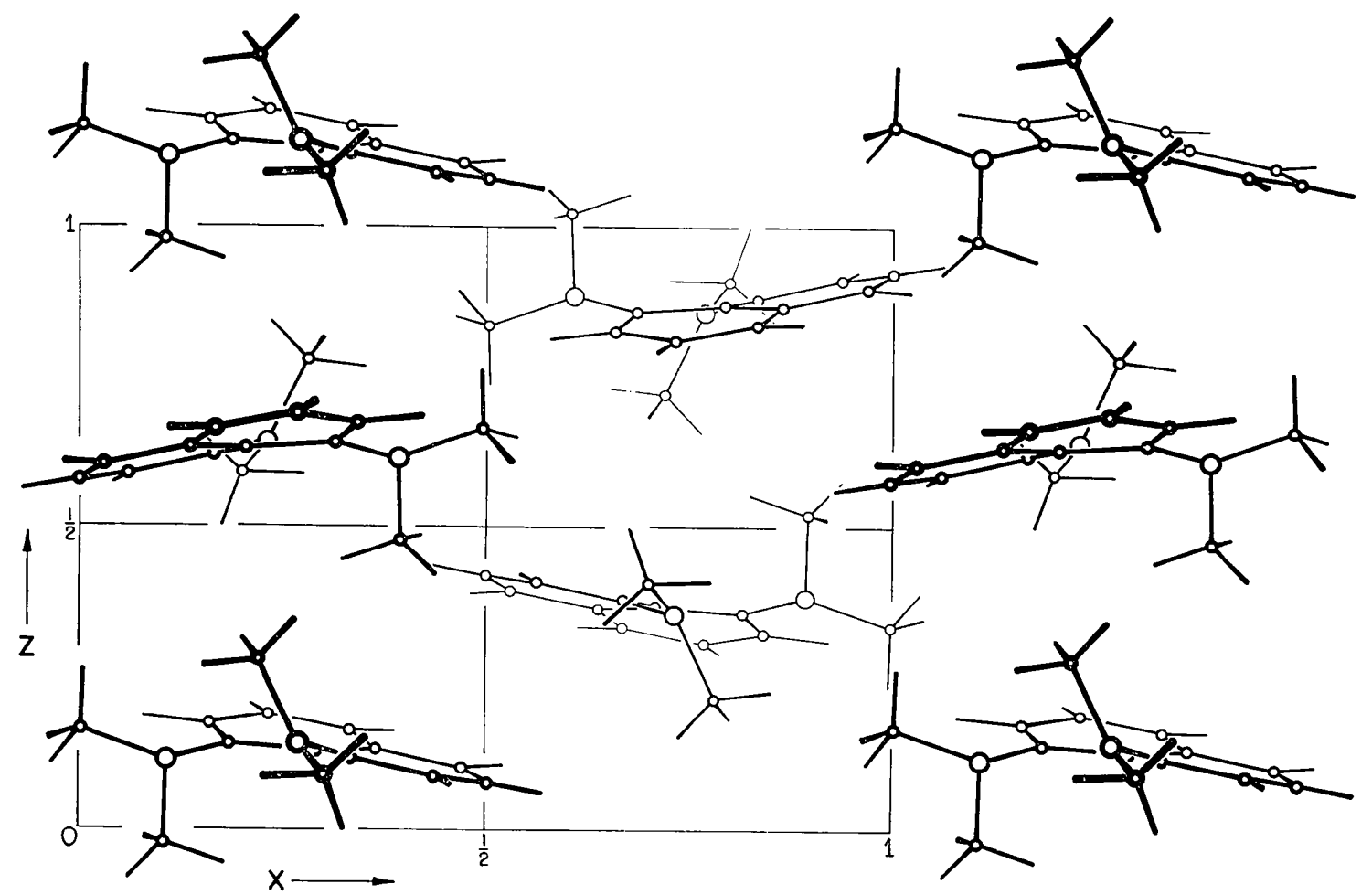

Fig. 4. A representation of the structure viewed along $b$. 
The temperature-factor ellipsoids are shown in Fig. $2(a)$; lengths of the principal axes are listed in Table 5. A rigid-body treatment of the thermal motions (Schomaker \& Trueblood, 1968) is not entirely satisfactory, for the r.m.s. value of $\Delta U_{i j}, 0.0036 \AA^{2}$, is over twice as large as the average standard deviation in these parameters (Table 2). Nevertheless, the treatment suggests that the principal axes of libration are approximately coincident with the axes of inertia of the molecule; the mean-square amplitudes are about $19^{\circ 2}$ for the librations in-plane and about the $\mathrm{C}(9)-\mathrm{C}(10)$ axis, and about $12^{\circ 2}$ about the third axis. Implied corrections to bond distances are approximately constant at $0.006 \AA$ for all $\mathrm{C}-\mathrm{C}$ and $\mathrm{C}-\mathrm{N}$ bonds; we have ignored these corrections.

The arrangement of the molecules in the crystal is shown in Fig. 4.

\section{Table 5. Analysis of the thermal ellipsoids}

The first three columns contain mean square amplitudes of vibration along the principal axes, and their e.s.d.'s (in parentheses). The final three columns contain the e.s.d.'s in the orientations of the ellipsoids, expressed as angular displacements (in degrees) about the major, intermediate and minor axes, respectively (Lindblom, Marsh \& Waser, 1972).

\begin{tabular}{lrlllll} 
& \multicolumn{1}{c}{$V_{1} \times 10^{-3}$} & $V_{2} \times 10^{-3}$ & $V_{3} \times 10^{-3}$ & $\alpha$ & $\beta$ & $\gamma$ \\
$\mathrm{C}(1)$ & $60(1) \AA^{2}$ & $49(1) \AA^{2}$ & $42(1) \AA^{2}$ & $7^{\circ}$ & $3^{\circ}$ & $4^{\circ}$ \\
$\mathrm{C}(2)$ & $76(2)$ & $67(2)$ & $56(1)$ & 5 & 3 & 7 \\
$\mathrm{C}(3)$ & $102(2)$ & $85(2)$ & $52(1)$ & 2 & 2 & 4 \\
$\mathrm{C}(4)$ & $103(2)$ & $64(1)$ & $42(1)$ & 3 & 1 & 2 \\
$\mathrm{C}(5)$ & $101(2)$ & $64(1)$ & $57(1)$ & 10 & 2 & 2 \\
$\mathrm{C}(6)$ & $125(2)$ & $79(2)$ & $46(1)$ & 2 & 1 & 2 \\
$\mathrm{C}(7)$ & $93(2)$ & $72(2)$ & $55(1)$ & 4 & 2 & 4 \\
$\mathrm{C}(8)$ & $61(1)$ & $53(1)$ & $44(1)$ & 6 & 4 & 7 \\
$\mathrm{C}(9)$ & $55(1)$ & $46(1)$ & $37(1)$ & 6 & 3 & 6 \\
$\mathrm{C}(10)$ & $73(1)$ & $49(1)$ & $42(1)$ & 8 & 2 & 2 \\
$\mathrm{~N}(11)$ & $72(1)$ & $55(1)$ & $41(1)$ & 3 & 1 & 3 \\
$\mathrm{~N}(12)$ & $77(1)$ & $59(1)$ & $45(1)$ & 4 & 2 & 3 \\
$\mathrm{C}(13)$ & $90(2)$ & $73(2)$ & $48(1)$ & 2 & 2 & 5 \\
$\mathrm{C}(14)$ & $110(2)$ & $90(2)$ & $52(1)$ & 2 & 1 & 4 \\
$\mathrm{C}(15)$ & $132(2)$ & $95(2)$ & $53(1)$ & 2 & 1 & 3 \\
$\mathrm{C}(16)$ & $95(2)$ & $80(2)$ & $50(1)$ & 2 & 2 & 5
\end{tabular}

\section{Concluding remarks}

The molecule appears to have accommodated the bulky peri substituents with surprisingly little strain. The $\mathrm{C}$ (ring)- $\mathrm{N}$ bonds have retained a significant amount of $\pi$ character, and two of the $\mathrm{N}-\mathrm{C}$ (methyl) bonds have remained in the plane of the aromatic ring system. Close interlocking of the hydrogen atoms is a key to the molecular conformation. The hydrogen atoms of methyl groups $C(14)$ and $C(15)$ are neatly staggered with respect to the ring atoms $\mathrm{H}(17)$ and $\mathrm{H}(22)$, while $\mathrm{H}(33)$ and $\mathrm{H}(62)$ of the other methyl groups are approximately centered above and below the $\mathrm{N}(11)-\mathrm{C}(1)-\mathrm{C}(9)-\mathrm{C}(8)-$ $\mathrm{N}(12)$ crescent. The conformation seems to be exceptionally rigid; the temperature parameters of the methyl hydrogen atoms are only slightly larger than those of the carbon atoms, and the asymmetry of the crystal forces (Fig. 4) has not been sufficient to destroy the nearly exact twofold symmetry of the molecule.

The $p \mathrm{~K}_{a}$ value for this compound in water is about 12 , as compared to values between 5 and 6 for the unmethylated or monomethylated species (Alder, Bowman, Steele \& Winterman, 1968). The remarkable basicity makes it a stable cation. Fenton, Truter \& Vickery (1971) have reported preliminary results of crystal structure studies of salts of this cation with tris(hexafluoroacetylacetonato)copper(II) and with the isomorphous magnesium derivative. In these compounds the nitrogen atoms and the cationic hydrogen atom are apparently in the plane of the ring system, the dimethylamino groups having been slightly rotated so that the methyl groups are symmetrically disposed above and below the plane of the naphthalene ring (conformation II, Introduction). The $\mathrm{N} \cdots \mathrm{N}$ distance is $2.62 \AA$, corresponding to a very strong hydrogen bond.

We are grateful to Dr Sten Samson for assembling and maintaining the diffraction equipment and to Miss Lillian Casler for much of the illustrative work.

\section{References}

Akopyan, Z. A., Kitaigorodskil, A. I. \& Struchkov, YU. T. (1965). Zh. Strukt. Khim. 6, 729-744.

Alder, R. W., Bowman, P. S., Steele, W. R. S. \& WinterMAN, D. R. (1968). Chem. Commun. pp. 723-724.

Anderson, J. E., Franck, R. W. \& Mandella, W. L. (1972). J. Amer. Chem. Soc. 94, 4608-4614 and references therein.

Balasubramaniyan, V. (1966). Chem. Rev. 66, 567-641.

Bondi, A. (1965). J. Phys. Chem. 68, 441-451.

Fenton, D. E., Truter, M. R. \& Vickery, B. L. (1971). Chem. Commun. pp. 93-94.

International Tables for X-ray Crystallography (1962). Vol. III, pp. 202-203. Birmingham: Kynoch Press.

Jameson, M. B. \& Penfold, B. R. (1965). J. Chem. Soc. pp. $528-536$.

JoHnson, C. K. (1965). ORTEP: A Fortran ThermalEllipsoid Plot Program for Crystal Structure Illustrations. Report ORNL-3794, Oak Ridge National Laboratory, Oak Ridge, Tennessee.

Larson, A. C. (1967). Acta Cryst. 23, 664-665.

Lindblom, L., Marsh, R. E. \& Waser, J. (1972). Acta Cryst. B 28, 2198-2201.

MARSh, R. E., Bierstedt, R. \& EICHHORN, E. L. (1962). Acta Cryst. 15, 310-316.

Pawley, G. S. \& Yeats, E. A. (1969). Acta Cryst. B25, 2009-2013.

Robert, J. B., Sherfinski, J. S. \& Roberts, J. D. (1973). To be published.

ROBERTS, J. D. (1961). Notes on Molecular Orbital Calculations, pp. 52-55, 77-79. New York: Benjamin.

Schomaker, V. \& Trueblood, K. N. (1968). Acta Cryst. B24, 63-76.

Scott, R. A. \& Scheraga, H. A. (1965). J. Chem. Phys. 42, 2209-2215.

Stewart, R. F., Davidson, E. R. \& Simpson, W. T. (1965). J. Chem. Phys. 42, 3175-3187.

Wheland, G. W. (1955). Resonance in Organic Chemistry, pp. 233-234, 372-375. New York: John Wiley. 